\title{
A new method for quantification of the phase selective localization of hybrid fillers in rubber blends
}

\author{
H. H. Le ${ }^{*}$ X. T. Hoang, U. Reuter, A. Janke, A. Das, S. Wiessner \\ Leibniz-Institut für Polymerforschung Dresden e.V., D-01069 Dresden, Germany
}

Received 14 July 2020; accepted in revised form 1 October 2020

\begin{abstract}
A new method for the quantitative description of the phase-specific localization of hybrid fillers in rubber blends was developed based on the wetting concept. Using the new concept, the kinetics of phase-specific localization of silica (Si)/carbon black (CB) hybrid fillers in styrene-butadiene rubber (SBR)/natural rubber (NR) blends was experimentally characterized during the single-step mixing and the multi-step mixing process. It could point out that the localization of the hybrid fillers at the end of the mixing process always reaches the stationary stage regardless of the mixing regime. The stationary state of filler localization is related to the migration of silica and CB during the mixing process, determined by the thermodynamic driving forces and well predicted by the $Z$ model. The adsorption of the curing additives on the filler surface markedly alters the surface energy of silica and $\mathrm{CB}$, which in turn influences the localization of hybrid fillers in rubber blends, particularly at low filler loading. That is why the morphological investigation made by electron microscopy for low filled rubber blends can hardly be applied to describe the filler localization of hybrid fillers in rubber blends at high filler loading.
\end{abstract}

Keywords: mechanical properties, hybrid fillers, rubber blends, selective filler localization

\section{Introduction}

The steady development in the tire industry is characterized by a simultaneous improvement in service life and safety, along with the reduction of fuel consumption. These requirements are in conflict with each other, and usually, an unsatisfactory compromise can be found. For example, a low hysteresis loss for reduction of fuel consumption requires a compound with low filler content and a high degree of crosslinking, that however leads to low rigidity, crack, and abrasion resistance [1]. In order to ensure an optimal balance of properties, various approaches in rubber technology have already been implemented. In addition to the chemical and structural modification of the rubber matrix and filler and the optimization of the formulation and mixing technology, the use of hybrid fillers is also a promising strategy. Silica and carbon black (CB) have been used as dominant reinforcing fillers for many years, especially in tire compounds. Due to the different surface energies and thus, different levels of filler-rubber interactions, silica and CB have their specific advantages and disadvantages. For example, with increasing $\mathrm{Si} / \mathrm{CB}$ content, the abrasion resistance and wet skid resistance improve, but the rolling resistance also increases. Partial replacement of CB with silica in rubber compounds is common in the tire industry in order to obtain the advantages of the two fillers $[2,3]$. However, the previous studies with such hybrid fillers showed that the variation of the silica/CB ratio does not yet produce a synergistic effect with regard to the properties of the rubber mixture and its vulcanizates. The various typical properties of a rubber compound often showed a linear dependence on the silica/CB ratio. With the use of silica/CB hybrid fillers in rubber blends instead of single compounds, 
the authors attempted to exploit the advantages of all blend components for the tire properties $[4,5]$. In general, the fatigue behavior, rolling resistance, and heat build-up of the blends are improved with an increased silica/ $\mathrm{CB}$ ratio, while the elongation at break and the modulus of elasticity decrease. Despite efforts, the change in the properties of rubber blends containing hybrid fillers with the variation of the silica/CB ratio followed the typical linear course, as found in the case of the single compounds. It can be assumed that the desired synergistic properties of rubber blends with hybrid fillers can only be achieved through the right combination of filler and rubber components in the correct proportions.

In general, the localization of filler in multi-phase blends is a kinetic process, which is thermodynamically driven by the affinity of the filler to the polymeric blend components $[6,7]$. Opposing influences of polarity and viscosity can lead to the preferential location of the filler in the interphase $[8,9]$. The filler localization in polymer blends also depends on the type of mixing unit used and the mixing sequence [10, $11]$ as well as the processing and vulcanizing agents [12]. Schuster et al. [9], Meier et al. [10], Hess and Chirico [11], Massie et al. [13], and Sircar et al. [14] demonstrated that the phase selective localization of a filler significantly influences the hysteresis, abrasion resistance, tensile strength, and tear resistance as well as the fatigue behavior of rubber blends. While extensive knowledge about the filler localization and its influence on the mechanical properties of silica or CB filled rubber blends has been found in numerous research works in recent years, the available knowledge regarding rubber blends containing hybrid fillers has been still very limited and incomplete. The questions of how the hybrid fillers are selectively wetted by the individual rubber components during processing and how this complex process influences the resulting mechanical properties of rubber blends have not yet been investigated. A number of methods, including direct methods like transmission electron microscopy (TEM) [11], atomic force microscopy (AFM) [15] and Raman microimaging [16] or indirect methods based on thermogravimetric analysis (TGA) [17], magnetic resonance imaging (NMR) and dynamic differential calorimetry (DSC) [13] as well dynamic mechanical analysis (DMA) [7-9] was developed for characterizing the phase selective localization of a filler in rubber blends. However, up to date, these methods have not been able to be applied for rubber blends containing hybrid fillers. This is the motivation for the development of a fast and reliable method to characterize the phase selective localization of the hybrid fillers in rubber blends during the mixing process. In the last decade, we developed a new method based on the wetting behavior of filler by rubber components to characterize the morphology development in filled rubber blends during the mixing process [18]. Accordingly, the rubber layer bound on the filler surface of a filled rubber blend was determined from the extraction experiment and analyzed using TGA and Fourier transform infrared spectroscopy (FTIR). The phase-specific filler localization in the binary blend can be quantified by the amounts of the rubber layer of each rubber component. On the basis of this method, different works have been done for the explanation of the wetting, dispersion, and distribution process of fillers like silica $[19,20]$, CB $[21,22]$, CNTs $[23,24]$ and nanoclay [25] in binary and ternary rubber blends. In the present work, an attempt has been made to further develop the wetting concept in order to characterize the phase selective localization of hybrid fillers $\mathrm{Si} / \mathrm{CB}$ in SBR/NR blends.

\section{Experimental}

\subsection{Materials and mixture preparation}

Solution styrene-butadiene rubber (S-SBR) used was SPRINTANTM SLR4602 (Trinseo Deutschland $\mathrm{GmbH}$ ) with a styrene content of $21 \%$, vinyl content of $63 \%$, and Mooney viscosity ML $1+4\left(100^{\circ} \mathrm{C}\right)$ of 65 MU. Natural rubber (NR) Standard Vietnamese Rubber (SVR10) (Weber \& Schaer GmbH) was used as a blend component. NR was masticated by means of a two-roll mill (Polymix 110L) at a temperature of $50^{\circ} \mathrm{C}$ and a gap size of $1.5 \mathrm{~mm}$ before use in order to obtain Mooney viscosity similar to SBR. Silica (Si) was Ultrasil 7000GR (Evonik) with the specific surface area CTAB of $160 \mathrm{~m}^{2} / \mathrm{g}$, and carbon black (CB) was Corax N220 (Orion) having CTAB surface area of $106 \mathrm{~m}^{2} / \mathrm{g}$. The amount of rubber, fillers, and additives used in the study were varied in parts per hundred rubber [phr]. The curing package consists of $3 \mathrm{phr} \mathrm{ZnO}, 1 \mathrm{phr}$ stearic acid, $1.5 \mathrm{phr}$ sulfur, and $1 \mathrm{phr} n$-cyclohexyl-2-benzothiazole-sulfenamide (CBS). All the mixing experiments were carried out in a HAAKE PolyLab OS (Rheo Drive 7) of Thermo Scientific with a total volume of $75 \mathrm{ml}$ and Banbury type rotors. All mixtures were mixed at a chamber temperature of $50^{\circ} \mathrm{C}$, a rotor speed of $50 \mathrm{rpm}$, and a 
fill factor of 0.68 . The rubber was first added to the mixing chamber. Silica, $\mathrm{CB}$, and hybrid fillers $\mathrm{Si} / \mathrm{CB}$, respectively, were added in the chamber at 2 min mixing time. The curing package was added to the mixture at 20 min mixing time, and the mixing process was stopped at $24 \mathrm{~min}$.

Two series of single compounds (S1 to S6 and S7 to S12) were prepared by compounding SBR and NR,

Table 1. Formulation of different single mixtures.

\begin{tabular}{|c|c|c|c|c|}
\hline Compound & $\begin{array}{l}\text { SBR } \\
\text { [phr] }\end{array}$ & $\begin{array}{c}\text { NR } \\
\text { [phr] }\end{array}$ & $\begin{array}{l}\text { Silica } \\
{[\mathbf{p h r}]}\end{array}$ & $\begin{array}{c}\text { CB } \\
{[p h r]}\end{array}$ \\
\hline S1 & \multirow{6}{*}{100} & \multirow{6}{*}{0} & 50 & 0 \\
\hline $\mathrm{S} 2$ & & & 40 & 10 \\
\hline S3 & & & 30 & 20 \\
\hline S4 & & & 20 & 30 \\
\hline S5 & & & 10 & 40 \\
\hline S6 & & & 0 & 50 \\
\hline S7 & \multirow{6}{*}{0} & \multirow{6}{*}{100} & 0 & 50 \\
\hline S8 & & & 10 & 40 \\
\hline S9 & & & 20 & 30 \\
\hline S10 & & & 30 & 20 \\
\hline S11 & & & 40 & 10 \\
\hline $\mathrm{S} 12$ & & & 50 & 0 \\
\hline
\end{tabular}

Table 2. Formulation of highly filled and low filled SBR/NR blend.

\begin{tabular}{|l|c|c|}
\hline \multicolumn{1}{|c|}{ Ingredient } & $\begin{array}{c}\text { B7 } \\
\text { [phr] }\end{array}$ & $\begin{array}{c}\text { B8 } \\
\text { [phr] }\end{array}$ \\
\hline SBR & 50 & 50 \\
\hline NR & 50 & 50 \\
\hline Silica & 25 & 3 \\
\hline CB & 25 & 3 \\
\hline
\end{tabular}

Table 3. Formulation of different Si/CB filled SBR/NR.

\begin{tabular}{|c|c|c|}
\hline Blend & \multicolumn{2}{|c|}{ Mixing of masterbatches } \\
\hline $\mathbf{1 0 0} \mathbf{w t} \%$ & $\mathbf{5 0} \mathbf{w t} \%$ & $\mathbf{5 0} \mathbf{w t} \%$ \\
\hline B1 & S1 & S7 \\
\hline B2 & S2 & S8 \\
\hline B3 & S3 & S9 \\
\hline B4 & S4 & S10 \\
\hline B5 & S5 & S11 \\
\hline B6 & S6 & S12 \\
\hline
\end{tabular}

Table 4. Formulation of rubber blends used for the production of a calibration curve.

\begin{tabular}{|l|c|c|c|c|c|c|c|}
\hline Ingredients & \multicolumn{7}{|c|}{$\begin{array}{c}\text { Composition } \\
\text { [wt\%] }\end{array}$} \\
\hline SBR & 20 & 30 & 40 & 50 & 60 & 70 & 80 \\
\hline NR & 80 & 70 & 60 & 50 & 40 & 30 & 20 \\
\hline
\end{tabular}

respectively, with hybrid fillers $\mathrm{Si} / \mathrm{CB}$ with varied mass ratios (Table 1). A 25/25 Si/CB filled SBR/NR blend (highly filled blend B7) was prepared according to Table 2 by means of single-step mixing for $24 \mathrm{~min}$. Along the mixing process of the blends, an amount of mixture of two grams was collected at 9, 14,19 , and $24 \mathrm{~min}$ in order to characterize the kinetics of hybrid filler localization in rubber blends.

A $3 / 3 \mathrm{Si} / \mathrm{CB}$ filled SBR/NR blend (low filled blend B8) was prepared for morphological investigation (Table 2). Aiming to prepare SBR/NR blends with desired phase selective Si/CB localization, we applied the multi-step mixing (masterbatch mixing) according to Table 3. Two masterbatches from series $\mathrm{S}$ were mixed with each other for 15 min by keeping the SBR/NR ratio by $50 / 50$ and silica/CB loading by $25 / 25 \mathrm{phr}$. Unfilled SBR/NR blends were prepared according to the formulation given in Table 4 for the creation of a calibration curve by means of Fourier transform infrared spectroscopy (FTIR). The curing process of the rubber compounds (vulcanization) was conducted using a hot-press at $160^{\circ} \mathrm{C}$ with the optimum cure time $\left(t_{90}\right)$, which was predetermined from the rubber process analyzer (Scarabaeus V-50, Germany). For each mixture, a sheet with a thickness of $2 \mathrm{~mm}$ was produced for morphological and mechanical testing.

\subsection{Characterization methods}

Transmission electron microscopy (TEM)

TEM measurements were performed on a TEM LIBRA 120 MC (Carl Zeiss SMT, Oberkochen, Germany) with an acceleration voltage of $120 \mathrm{kV}$. For this, ultrathin sections with approximately $60 \mathrm{~nm}$ thickness were cut with a diamond knife $\left(35^{\circ}\right.$ cut angle, DIATOME, Switzerland) on a cryo-ultramicrotome EM UC6/FC6 (Leica, Austria) at $-160^{\circ} \mathrm{C}$. The sections were collected on carbon-coated copper grids.

\section{Atomic force microscopy}

Atomic force microscope (AFM) investigation of filler distribution was carried out on a Dimension FastScan in PF-QNM mode using FastScan-A cantilever (both Bruker-Nano Inc., Santa Barbara, CA). The maximum force in PF-QNM mode was in the range of $20-30 \mathrm{nN}$ leading to a maximum deformation of $50 \mathrm{~nm}$ in the rubber phase. The scanning rate and digital resolution were $0.5 \mathrm{~Hz}$ and 512 pixel $\times$ 512 pixel, respectively. All samples were prepared 
as truncated pyramid by cutting with a diamond knife ( $35^{\circ}$ cut angle, DIATOME, Switzerland) on a cryoultramicrotome EM UC6/FC6 (Leica, Austria) at $-160{ }^{\circ} \mathrm{C}$.

\section{Extraction experiment}

$0.2 \mathrm{~g}$ of the uncured mixture was stored in a stoppered bottle with $150 \mathrm{ml}$ of cyclohexane and xylene, respectively, at room temperature for seven days. During this time period, the unbound rubber molecules were dissolved in the solvent. The solution was cast from the bottle, and the gel was taken out, dried, and preserved for further investigation.

\section{Fourier transform infrared spectroscopy (FTIR)}

The unfilled rubber blends were subjected to FTIR analysis (Bruker Tensor 27) equipped with a diamond ATR cell to draw the calibration curve. The specimen was collected from six different places of a sample, and an average of six measurements was taken for further evaluation. All the scans were done in the range of $4000-400 \mathrm{~cm}^{-1}$ wavelength, with a resolution of $2 \mathrm{~cm}^{-1}$. An average of 32 scans was recorded each time. The characteristic peak of SBR at $910 \mathrm{~cm}^{-1}$ (bending vibration of the vinyl group) and NR phase at $1376 \mathrm{~cm}^{-1}$ (bending vibration of $-\mathrm{CH}$ ) were used for FTIR evaluation in the present work. Due to the strong absorbing character, it was not possible to apply the FTIR method with diamond ATR cell for CB containing rubber blends and gels, respectively. In recent times thanks to the modernization of the FTIR technique, i.e., the use of germanium crystal in the instrument

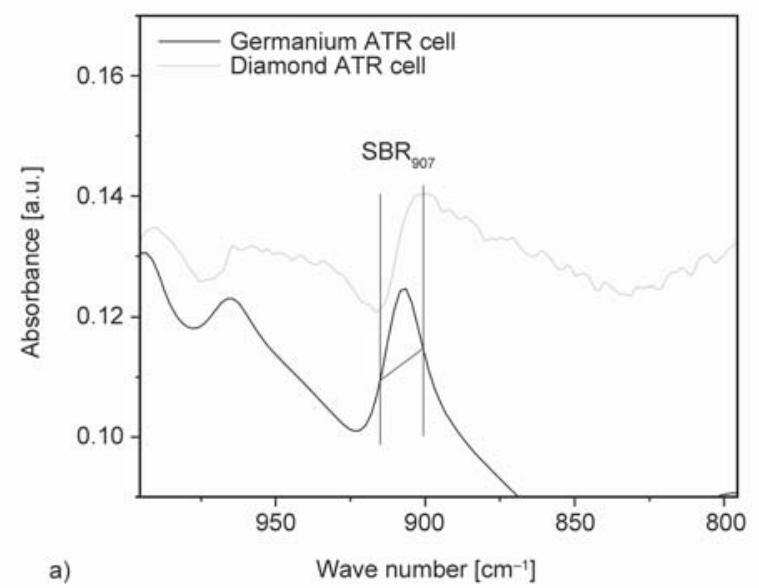

instead of a diamond crystal, it is now possible to detect IR spectra of rubber samples containing a high amount $\mathrm{CB}$.

The gels obtained from the extraction experiment were characterized with germanium crystal ATRFTIR equipment (Vertex 80v, Bruker). All the scans were done in the range of $4000-600 \mathrm{~cm}^{-1}$ wavelength, with a resolution of $4 \mathrm{~cm}^{-1}$. An average of 100 scans was recorded each time.

Spectral of a gel of a 25/25 Si/CB filled blend were recorded by diamond and germanium ATR cell and representatively shown in Figure 1. The peak of SBR at $910 \mathrm{~cm}^{-1}$ presented in Figure 1a and NR at $1374 \mathrm{~cm}^{-1}$ in Figure $1 \mathrm{~b}$ are visual clearly by means of the germanium ATR cell, while very weak and unevaluable signals were detected from the diamond ATR cell.

\section{Tensile test}

Stress-strain measurements were performed according to ISO 37 using a tensile tester Z010 (Zwick/ Roell) with a cross-head speed of $200 \mathrm{~mm} \cdot \mathrm{min}^{-1}$ at room temperature. The test specimens had a thickness of $1.3 \mathrm{~mm}$ and an initial length of $30 \mathrm{~mm}$. All data presented are the average of five measured specimens for each sample.

\section{Tearing test}

The tear property was measured according to DIN ISO 34-1 method A using a tensile tester UPM zwicki-2.5 (Zwick/Roell) with a cross-head speed of $100 \mathrm{~mm} \cdot \mathrm{min}^{-1}$ at room temperature with $1 \mathrm{kN}$ of the load cell.

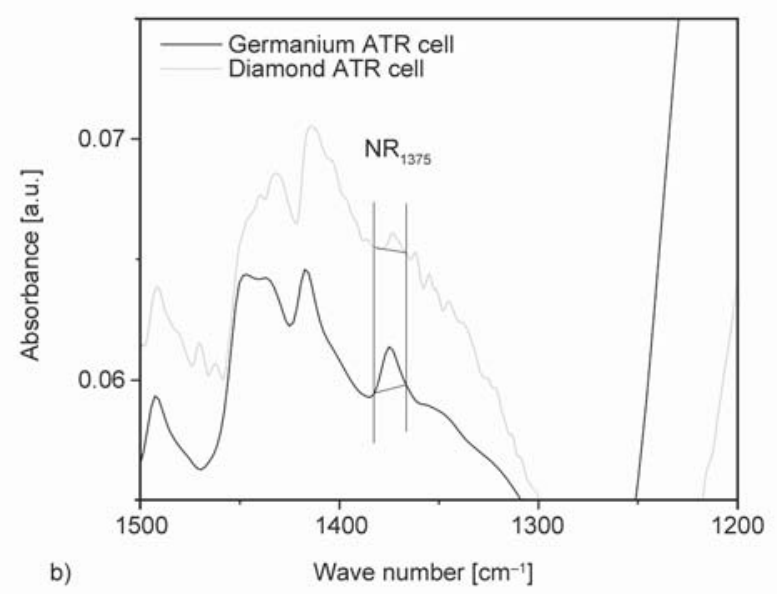

Figure 1. FTIR spectral of a gel of a Si/CB filled SBR/NR blend received from xylene extraction recorded by diamond and germanium ATR (SBR peak (a) and NR peak (b)). 


\section{Results and discussion}

\subsection{Prediction of the phase selective localization of $\mathrm{Si} / \mathrm{CB}$ in SBR/NR blend using the $Z$ model}

On the basis of the $\mathrm{Z}$ model for a binary rubber blend filled with a single filler proposed in our previous work [12], the phase selective localization of hybrid fillers in rubber blends at the thermodynamic equilibrium state can be predicted according to Equations (1) and (2):

$$
\begin{aligned}
\frac{F_{\mathrm{eq}}^{\mathrm{NR}}}{F_{\mathrm{eq}}^{\mathrm{SBR}}} & =n_{\mathrm{NR} / \mathrm{SBR}}\left(\frac{\gamma_{\mathrm{SBR}-\mathrm{F}}}{\gamma_{\mathrm{NR}-\mathrm{F}}}\right)^{2}= \\
& =n_{\mathrm{NR} / \mathrm{SBR}}\left(\frac{\gamma_{\mathrm{SBR}}+\gamma_{\mathrm{F}}-2 \sqrt{\gamma_{\mathrm{SBR}} \gamma_{\mathrm{F}}}}{\gamma_{\mathrm{NR}}+\gamma_{\mathrm{F}}-2 \sqrt{\gamma_{\mathrm{NR}} \gamma_{\mathrm{F}}}}\right)^{2} \\
F_{\mathrm{eq}}^{\mathrm{NR}} & +F_{\mathrm{eq}}^{\mathrm{SBR}}=50
\end{aligned}
$$

where $F_{\text {eq }}^{\mathrm{SBR}}$ and $F_{\text {eq }}^{\mathrm{NR}}$ are the filler loading localized in the SBR, and NR phase of SBR/NR blends at the equilibrium state. $n_{\mathrm{NR} / \mathrm{SBR}}$ is the mass ratio of NR to SBR in the blend. $\gamma_{\mathrm{SBR}-\mathrm{F}}$ and $\gamma_{\mathrm{NR}-\mathrm{F}}$ are the interfacial tensions between the polymer and the filler. $\gamma_{\mathrm{SBR}}$, $\gamma_{\mathrm{NR}}$, and $\gamma_{\mathrm{F}}$ are the surface tension values of the rubber components and the filler, respectively. In the present work $\gamma_{\mathrm{SBR}}=24 \mathrm{mN} \cdot \mathrm{m}^{-1}[24], \gamma_{\mathrm{NR}}=$ $22 \mathrm{mN} \cdot \mathrm{m}^{-1}$ [24], and $\gamma_{\mathrm{F}}=71 \mathrm{mN} \cdot \mathrm{m}^{-1}$ for silica [26] and $\gamma_{\mathrm{F}}=30.5 \mathrm{mN} \cdot \mathrm{m}^{-1}$ for $\mathrm{CB}$ [27] were used.

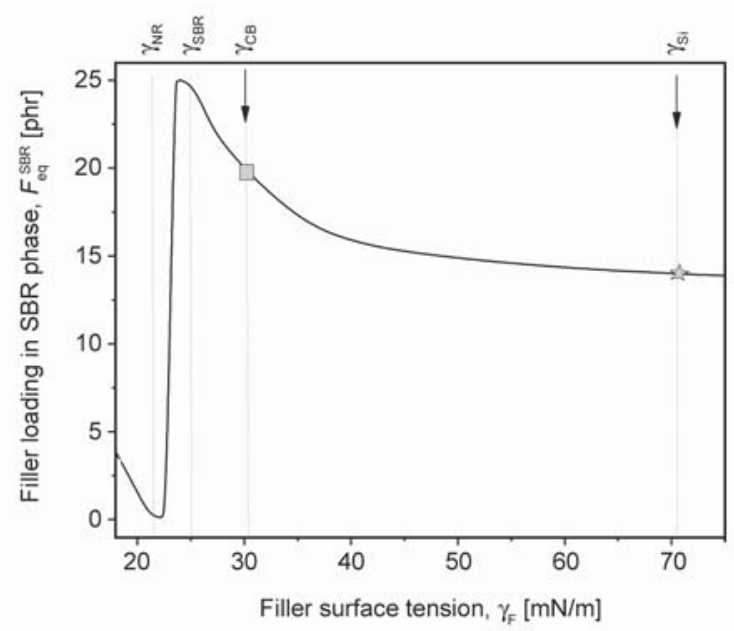

Figure 2. Prediction of phase selective silica and CB localization in 25/25 Si/CB filled SBR/NR blend using the $Z$ model.
By inserting the surface tension values $\gamma_{\mathrm{SBR}}$ and $\gamma_{\mathrm{NR}}$ of SBR and NR, respectively, into the $Z$ model with $n_{\mathrm{NR} / \mathrm{SBR}}=1$ for $50 / 50 \mathrm{SBR} / \mathrm{NR}$ blend, a Z-shaped master curve can be created, demonstrating the filler localized in the SBR phase $F_{\text {eq }}^{\mathrm{SBR}}$ as a function of the filler surface tension as seen in Figure 2. By fitting the surface tension of silica and $\mathrm{CB}$ to the master curve, silica, and CB loading in each blend phase of the blend were determined and given in Table 5. It is clearly observed that silica and CB are preferentially localized in the SBR phase.

\subsection{Further development of the wetting concept for experimental determination of the phase-specific localization of $\mathrm{Si} / \mathrm{CB}$ in SBR/NR blends}

The wetting concept was developed to describe the wetting behavior of the filler by different rubber components in blends $[23,28]$. It was also applied to determine the phase specific localization of filler in rubber blends experimentally because the ability of the rubber to wet the surface of the filler is closely correlated to the amount of the filler located in that rubber phase. Higher the ability of the rubber to wet the filler, the greater the amount of the filler distributed in that phase. By the addition of filler in a single rubber, a certain number of rubber chains gets attached to the active center of the filler. The mobility of the attached rubber chains is restricted, and so they cannot be extracted by a good solvent. The rubber layer $L$, which is defined as the fraction of nonextracted rubber part present in the rubber-filler gel, can be determined by Equation (3) $[23,28]$ :

$L=\frac{m_{2}-m_{1} \cdot c_{\mathrm{F}}}{m_{2}}$

where $m_{1}$ is the mass of uncured rubber-filler compound prior to extraction, $m_{2}$ corresponds to the mass of rubber-filler gel. The weight fraction of filler in the compound is designated by $c_{\mathrm{F}}$.

The rubber layer $L$ increases as a function of mixing time $t$ and reaches the plateau value designated by $L_{\mathrm{P}}$, corresponds to the condition when all the active centers of the filler are attached with rubber chains. $L_{\mathrm{P}}$ reaches the plateau value experimentally at a mixing time exceeding $10 \min [12,21]$.

Table 5. Phase selective localization of $\mathrm{Si} / \mathrm{CB}$ in $\mathrm{SBR} / \mathrm{NR}$ blend predicted by the $Z$ model.

\begin{tabular}{|c|c|c|c|c|}
\hline Blend & Si in SBR & Si in NR & CB in SBR & CB in NR \\
\hline $25 / 25 \mathrm{Si} / \mathrm{CB}$ filled SBR/NR blend & 15 & 10 & 19.3 & 5.7 \\
\hline
\end{tabular}


Depending on the nature and strength of the rubberfiller interactions, the filled mixtures show a characteristic dependence of the rubber layer on the used solvent that plays an important role in the further development of the wetting concept. In the present work, cyclohexane and xylene were chosen as suitable solvents for the extraction of $\mathrm{Si} / \mathrm{CB}$ filled $\mathrm{SBR} / \mathrm{NR}$ blends. The plateau value of the rubber layer $L_{\mathrm{P}}$ of the filled SBR and NR mixtures was determined experimentally using Equation (3). The ratio between $L_{\mathrm{P}}$ from xylene and cyclohexane extraction, respectively, is described by a factor $k$ according to Equation (4)-(7):

$$
\begin{aligned}
& \frac{{ }_{\mathrm{xy}}^{\mathrm{Si}} L_{\mathrm{P}}^{\mathrm{SBR}}}{{ }_{\mathrm{cy}} L_{\mathrm{P}}^{\mathrm{SBR}}}=k_{\mathrm{Si} / \mathrm{SBR}} \\
& \frac{{ }_{\mathrm{xy}}^{\mathrm{Si}} L_{\mathrm{P}}^{\mathrm{NR}}}{{ }_{\mathrm{cy}} L_{\mathrm{P}}^{\mathrm{NR}}}=k_{\mathrm{Si} / \mathrm{NR}} \\
& \frac{{ }_{\mathrm{xy}}^{\mathrm{CB}} L_{\mathrm{P}}^{\mathrm{SBR}}}{{ }_{\mathrm{cy}}^{\mathrm{CB}} L_{\mathrm{P}}^{\mathrm{SBR}}}=k_{\mathrm{CB} / \mathrm{SBR}} \\
& \frac{{ }_{\mathrm{xy}}^{\mathrm{CB}} L_{\mathrm{P}}^{\mathrm{NR}}}{{ }_{\mathrm{cy}} \mathrm{N} L_{\mathrm{P}}^{\mathrm{NR}}}=k_{\mathrm{CB} / \mathrm{NR}}
\end{aligned}
$$

where ${ }_{\mathrm{cy}}^{\mathrm{Si}} L_{\mathrm{P}}^{\mathrm{SBR}},{ }_{\mathrm{cy}}^{\mathrm{Si}} L_{\mathrm{P}}^{\mathrm{NR}},{ }_{\mathrm{cy}}^{\mathrm{CB}} L_{\mathrm{P}}^{\mathrm{SBR}}$, and ${ }_{\mathrm{cy}}^{\mathrm{CB}} L_{\mathrm{P}}^{\mathrm{NR}}$ are the plateau rubber layer of the $\mathrm{Si} / \mathrm{SBR}, \mathrm{Si} / \mathrm{NR}, \mathrm{CB} / \mathrm{SBR}$ and $\mathrm{CB} / \mathrm{NR}$ compound determined from the cyclohexane extraction. Accordingly, ${ }_{\mathrm{xy}}^{\mathrm{Si}} L_{\mathrm{P}}^{\mathrm{SBR}},{ }_{\mathrm{xy}}^{\mathrm{Si}} L_{\mathrm{P}}^{\mathrm{NR}},{ }_{\mathrm{xy}}^{\mathrm{CB}} L_{\mathrm{P}}^{\mathrm{S}}$ ${ }^{\mathrm{BR}}$, and ${ }_{\mathrm{xy}}^{\mathrm{CB}} L_{\mathrm{P}}^{\mathrm{NR}}$ were received from the xylene extraction. The difference in $k$-values given in Table 6 indicates clearly the different responses of $\mathrm{Si} / \mathrm{SBR}$, $\mathrm{Si} / \mathrm{NR}$, and $\mathrm{CB} / \mathrm{SBR}$, as well as $\mathrm{CB} / \mathrm{NR}$ bondings to cyclohexane and xylene, respectively, which is essential for the sensitivity of the wetting concept.

Figure 3 illustrates the change in the rubber layer in $\mathrm{Si} / \mathrm{CB}$ filled SBR/NR blend after extraction with cyclohexane and xylene. The attached rubber layer becomes thinner if the rubber-filler bondings strongly respond to the solvent. The rubber layer ${ }_{\mathrm{cy}}^{\mathrm{Si} / \mathrm{CB}} L^{\mathrm{SBR} / \mathrm{NR}}(t)$ describes the bonded SBR/NR layer remaining on the $\mathrm{Si} / \mathrm{CB}$ surface after cyclohexane extraction. It consists of ${ }_{\mathrm{cy}}^{\mathrm{Si} / \mathrm{CB}} L^{\mathrm{SBR}}(t)$ and ${ }_{\mathrm{cy}}^{\mathrm{S} / \mathrm{CB}} L^{\mathrm{NR}}(t)$ according to Equation (8) and (9):

$$
\begin{aligned}
& { }_{\mathrm{cy}}^{\mathrm{Si} / \mathrm{CB}} L^{\mathrm{SBR} / \mathrm{NR}}(t)={ }_{\mathrm{cy}}^{\mathrm{Si} / \mathrm{CB}} L^{\mathrm{SBR}}(t)+{ }_{\mathrm{cy}}^{\mathrm{Si} / \mathrm{CB}} L^{\mathrm{NR}}(t) \\
& \frac{{ }_{\mathrm{cy}}^{\mathrm{Si} / \mathrm{CB}} L^{\mathrm{SBR}}(t)}{{ }_{\mathrm{cy}}^{\mathrm{Si} / \mathrm{CB}} L^{\mathrm{NR}}(t)}=\frac{1}{f_{\mathrm{SBR} / \mathrm{NR}}} \frac{A^{\mathrm{SBR}}(t)}{A^{\mathrm{NR}}(t)}
\end{aligned}
$$

where ${ }_{\mathrm{cy}}^{\mathrm{Si} / \mathrm{CB}} L^{\mathrm{SBR}}(t)$ and ${ }_{\mathrm{cy}}^{\mathrm{Si} / \mathrm{CB}} L^{\mathrm{NR}}(t)$ are the SBR and NR layer on the $\mathrm{Si} / \mathrm{CB}$ surface from cyclohexane extraction. For the determination of the mass of the rubber part in the gel using FTIR, a calibration curve describing the correlation between the area under the characteristic peaks and the rubber mass is required according to [12]. For this purpose, a series of binary blends SBR/NR was prepared according to Table 4 with different composition and subjected to FTIR study. The calibration curve shows the linear dependence of the ratio of the area under peak $A^{\mathrm{SBR}} / A^{\mathrm{NR}}$ on the mass ratio $\mathrm{Si} / \mathrm{CB} . A^{\mathrm{SBR}}$ and $A^{\mathrm{NR}}$ are the areas of a characteristic peak of the SBR phase at $910 \mathrm{~cm}^{-1}$ and NR phase at $1376 \mathrm{~cm}^{-1}$. The slope $f_{\mathrm{SBR} / \mathrm{NR}}=1.9$ was determined from the calibration curve. Using Equation (8) and (9), ${ }_{\mathrm{cy}}^{\mathrm{Si} / \mathrm{CB}} L^{\mathrm{SBR}}(t)$ and ${ }_{\mathrm{cy}}^{\mathrm{Si} / \mathrm{CB}} L^{\mathrm{NR}}(t)$ are determined.

The rubber layer ${ }_{\mathrm{xy}}^{\mathrm{S} / \mathrm{CB}} L^{\mathrm{SBR} / \mathrm{NR}}(t)$ of the $\mathrm{Si} / \mathrm{CB}$ filled $\mathrm{SBR} / \mathrm{NR}$ blend is determined analogously from $\mathrm{xy}-$ lene extraction. The rubber layer ${ }_{x y}^{\mathrm{Si} / \mathrm{CB}} L^{\mathrm{SBR} / \mathrm{NR}}(t)$ consists of ${ }_{\mathrm{xy}}^{\mathrm{Si} / \mathrm{CB}} L^{\mathrm{SBR}}(t)$ and ${ }_{\mathrm{xy}}^{\mathrm{Si} / \mathrm{CB}} L^{\mathrm{NR}}(t)$ (Equation (10) and (11)):

$$
\begin{aligned}
& { }_{\mathrm{xy}}^{\mathrm{Si} / \mathrm{CB}} L^{\mathrm{SBR} / \mathrm{NR}}(t)={ }_{\mathrm{xy}}^{\mathrm{Si} / \mathrm{CB}} L^{\mathrm{SBR}}(t)+{ }_{\mathrm{xy}}^{\mathrm{Si} / \mathrm{CB}} L^{\mathrm{NR}}(t) \\
& \frac{{ }_{\mathrm{xy}}^{\mathrm{Si} / \mathrm{CB}} L^{\mathrm{SBR}}(t)}{\underset{\mathrm{xy}}{\mathrm{Si} / \mathrm{CB}} L^{\mathrm{NR}}(t)}=\frac{1}{f_{\mathrm{SBR} / \mathrm{NR}}} \frac{A^{\mathrm{SBR}}(t)}{A^{\mathrm{NR}}(t)}
\end{aligned}
$$

where ${ }_{\mathrm{xy}}^{\mathrm{Si} / \mathrm{CB}} L^{\mathrm{SBR}}(t)$ and ${ }_{\mathrm{xy}}^{\mathrm{Si} / \mathrm{CB}} L^{\mathrm{NR}}(t)$ are the $\mathrm{SBR}$ and NR layer on the $\mathrm{Si} / \mathrm{CB}$ surface from xylene extraction. The ratio ${ }_{\mathrm{xy}}^{\mathrm{Si} / \mathrm{CB}} L^{\mathrm{SBR}}(t) /{ }_{\mathrm{xy}} \mathrm{Si} / \mathrm{CB} L^{\mathrm{NR}}(t)$ is calculated

Table 6. Plateau values of rubber layer $L_{\mathrm{P}}$ of the rubber compounds filled with silica and $\mathrm{CB}$, respectively, received from cyclohexane and xylene extraction and the related factor $k$.

\begin{tabular}{|c|c|c|c|}
\hline Plateau rubber layer & Cyclohexane extraction & Xylene extraction & $\boldsymbol{k}$ \\
\hline${ }^{\mathrm{Si}} L_{\mathrm{P}}^{\mathrm{SBR}}$ & 0.480 & 0.560 & $k_{\mathrm{Si} / \mathrm{SBR}}=1.170$ \\
\hline${ }^{\mathrm{CB}} L_{\mathrm{P}}^{\mathrm{SBR}}$ & 0.340 & 0.300 & $k_{\mathrm{CB} / \mathrm{SBR}}=0.880$ \\
\hline${ }^{\mathrm{Si}} L_{\mathrm{P}}^{\mathrm{NR}}$ & 0.434 & 0.417 & $k_{\mathrm{S} / \mathrm{NR}}=0.960$ \\
\hline${ }^{\mathrm{CB}} L_{\mathrm{P}}^{\mathrm{NR}}$ & 0.561 & 0.110 & $k_{\mathrm{CB} / \mathrm{NR}}=0.196$ \\
\hline
\end{tabular}



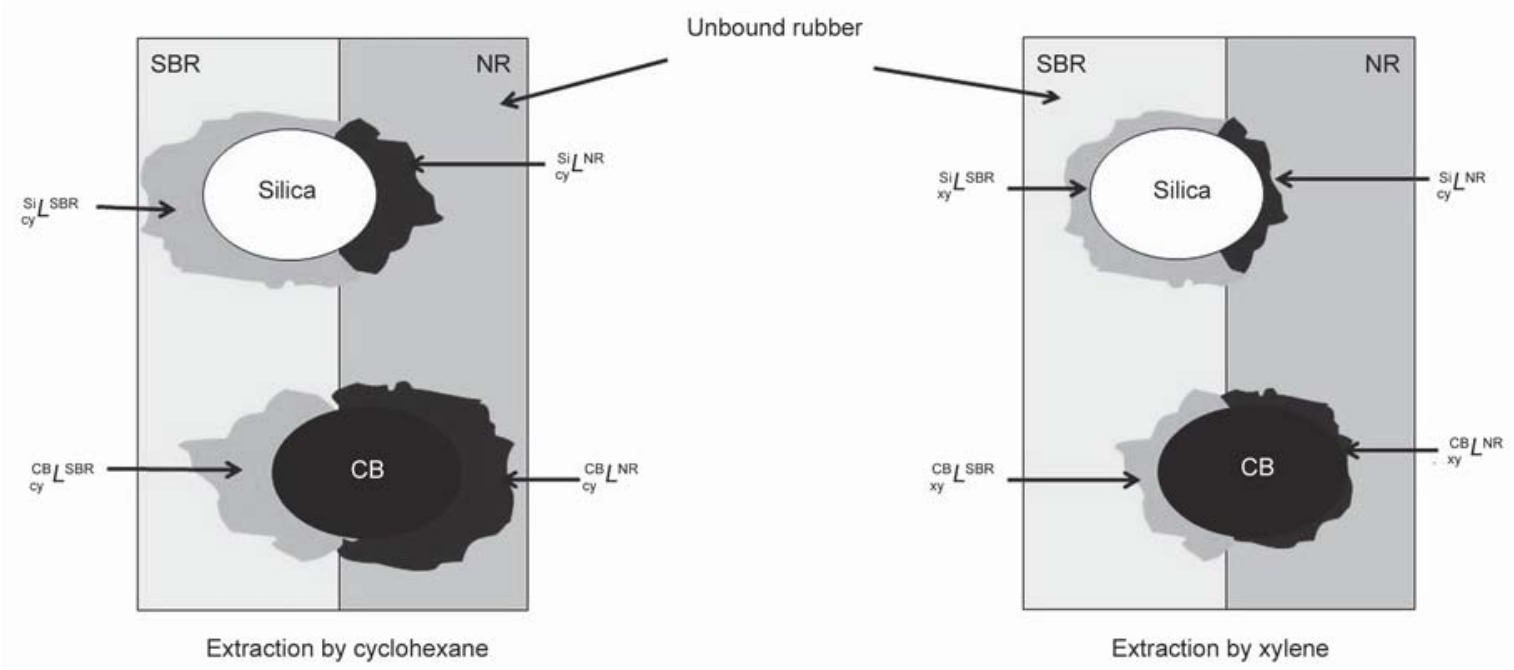

Figure 3. The rubber layer on silica and CB surface in SBR/NR blend representatively shown by cyclohexane (a) and xylene (b) extraction.

from the FTIR spectrum of the Si/CB filled SBR/NR gel from xylene extraction using Equation (11). Using Equations (10) and $(11),{ }_{\mathrm{xy}}^{\mathrm{Si} / \mathrm{CB}} L^{\mathrm{SBR}}(t)$ and ${ }_{\mathrm{xy}}^{\mathrm{Si} / \mathrm{CB}} L^{\mathrm{NR}}(t)$ are determined.

The SBR layer on the Si/CB surface consists of the SBR rubber layer on the silica and CB surface, respectively, in accordance with Equations (12) and (13):

$$
\begin{aligned}
& { }_{\mathrm{cy}}^{\mathrm{Si} / \mathrm{CB}} L^{\mathrm{SBR}}(t)={ }_{\mathrm{cy}}^{\mathrm{Si}} L^{\mathrm{SBR}}(t)+{ }_{\mathrm{cy}}^{\mathrm{CB}} L^{\mathrm{SBR}}(t) \\
& \mathrm{xi}_{\mathrm{xy}}^{\mathrm{CB}} L^{\mathrm{SBR}}(t)={ }_{\mathrm{xy}}^{\mathrm{Si}} L^{\mathrm{SBR}}(t)+{ }_{\mathrm{xy}}^{\mathrm{CB}} L^{\mathrm{SBR}}(t)
\end{aligned}
$$

Accordingly, the NR layer on the silica and CB surface, respectively, can be determined according to Equations (14) and (15):

$$
\begin{aligned}
& {\underset{c y}{\mathrm{Si}} / \mathrm{CB}}^{\mathrm{NR}}(t)={ }_{\mathrm{cy}}^{\mathrm{Si}} L^{\mathrm{NR}}(t)+{ }_{\mathrm{cy}}^{\mathrm{CB}} L^{\mathrm{NR}}(t) \\
& \underset{\mathrm{xy}}{\mathrm{Si} / \mathrm{CB}} L^{\mathrm{NR}}(t)={ }_{\mathrm{xy}}^{\mathrm{Si}} L^{\mathrm{NR}}(t)+{ }_{\mathrm{xy}}^{\mathrm{CB}} L^{\mathrm{NR}}(t)
\end{aligned}
$$

Equations (13) and (15) can be rewritten by taking into consideration the factor $k$ from Table 6 (Equations (16) and (17)):

$$
\begin{aligned}
& { }_{\mathrm{xy}}^{\mathrm{Si} / \mathrm{CB}} L^{\mathrm{SBR}}(t)= \\
& \quad={ }_{\mathrm{cy}}^{\mathrm{Si}} L^{\mathrm{SBR}}(t) \cdot k_{\mathrm{Si} / \mathrm{SBR}}+{ }_{\mathrm{cy}}^{\mathrm{CB}} L^{\mathrm{SBR}}(t) \cdot k_{\mathrm{CB} / \mathrm{SBR}} \\
& { }_{\mathrm{xy}}^{\mathrm{Si} / \mathrm{CB}} L^{\mathrm{NR}}(t)= \\
& \quad={ }_{\mathrm{cy}}^{\mathrm{Si}} L^{\mathrm{NR}}(t) \cdot k_{\mathrm{Si} / \mathrm{NR}}+{ }_{\mathrm{cy}}^{\mathrm{CB}} L^{\mathrm{NR}}(t) \cdot k_{\mathrm{CB} / \mathrm{NR}}
\end{aligned}
$$

Based on Equations (10), (14), (16) and (17) the rubber layer ${ }_{\mathrm{cy}}^{\mathrm{Si}} L^{\mathrm{SBR}},{ }_{\mathrm{cy}}^{\mathrm{Si}} L^{\mathrm{NR}},{ }_{\mathrm{cy}}^{\mathrm{CB}} L^{\mathrm{SBR}}$ and ${ }_{\mathrm{cy}}^{\mathrm{CB}} L^{\mathrm{NR}}$ can be determined. The filler content in the SBR and NR phase ${ }^{\mathrm{Si}} F^{\mathrm{SBR}},{ }^{\mathrm{Si}} F^{\mathrm{NR}},{ }^{\mathrm{CB}} F^{\mathrm{SBR}}$, and ${ }^{\mathrm{CB}} F^{\mathrm{NR}}$ of a $\mathrm{Si} / \mathrm{CB}$ filled SBR/NR blend can be determined according to Equations (18)-(21) according to [22]:

$$
\frac{{ }_{\mathrm{Si}} F^{\mathrm{SBR}}(t)}{{ }_{\mathrm{Si}} F^{\mathrm{NR}}(t)}=\frac{{ }_{\mathrm{cy}}^{\mathrm{Si}} L_{\mathrm{P}}^{\mathrm{NR}}}{{ }_{\mathrm{cy}} L_{\mathrm{P}}^{\mathrm{SBR}}} \cdot \frac{{ }_{\mathrm{cy}}^{\mathrm{Si}} L^{\mathrm{SBR}}(t)}{{ }_{\mathrm{cy}} L^{\mathrm{NR}}(t)}
$$

${ }^{\mathrm{Si}} F^{\mathrm{SBR}}(t)+{ }^{\mathrm{Si}} F^{\mathrm{NR}}(t)={ }^{\mathrm{Si}} F$

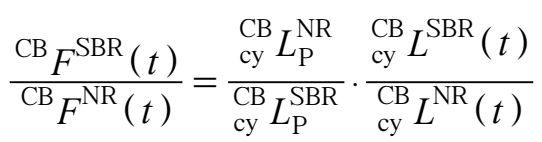

${ }^{\mathrm{CB}} F^{\mathrm{SBR}}(t)+{ }^{\mathrm{CB}} F^{\mathrm{NR}}(t)={ }^{C B} F$

where ${ }^{\mathrm{Si}} F$ and ${ }^{\mathrm{CB}} F$ are the total silica and $\mathrm{CB}$ loading in the filled SBR/NR blend. In the present work ${ }^{\mathrm{Si}} F=25 \mathrm{phr}$ and ${ }^{\mathrm{CB}} F=25 \mathrm{phr}$.

The kinetics of silica and CB localization in SBR/CB blend B7 is presented in Figure 4. It is clearly evident

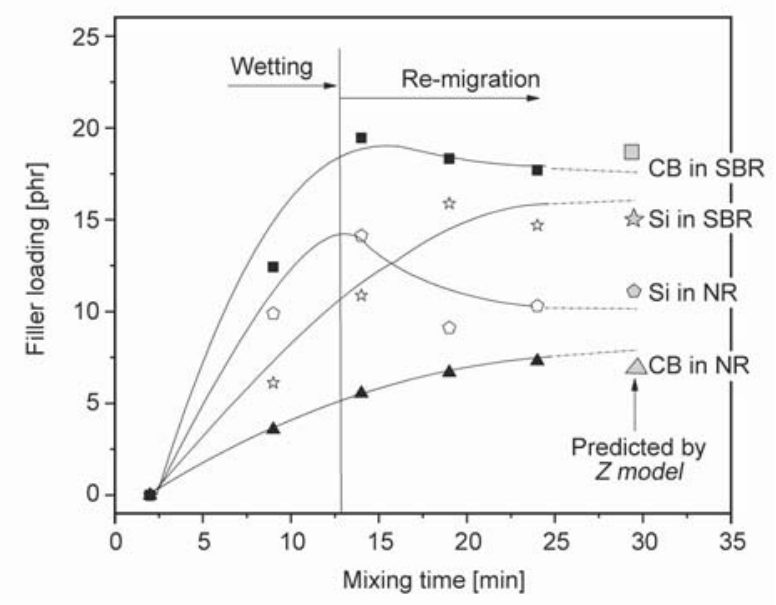

Figure 4. Kinetics of filler localization in Si/CB filled SBR/ NR blends determined using the wetting concept. 
that the rate of the wetting of silica by NR was much higher than that by SBR in the first mixing stage up to 13 min mixing time. In the second stage, after 13 min mixing time, silica loading decreases in the NR phase while it continuously increases in the SBR phase. That indicates a migration of silica from a thermodynamically less favorable phase to a thermodynamically more favorable one. The wetting behavior of silica in $\mathrm{Si} / \mathrm{CB}$ filled SBR/NR blends is similar to that of silica filled SBR/NR blends reported in our previous works [20]. Using the data from [20], the kinetics of silica localization in silica filled SBR/NR blend is reconstructed and presented in Figure 5a. Filler loading increases immediately after the addition. Thanks to the higher wetting rate, the NR chains can wet more silica than the SBR chains in the first mixing stage (up to $6 \mathrm{~min}$ ). In the second stage, from 6 to $14 \mathrm{~min}$, as discussed before, the loosely bonded component of NR chains is replaced by SBR chains. As a result, silica seems to transfer from the NR phase towards the SBR phase. After $14 \mathrm{~min}$, silica stops to go towards the SBR phase.

The wetting kinetics of CB by SBR and NR in B7 shows another trend. The SBR phase presents a fast CB wetting compared to the NR phase, which seems to be in contrast with our results found in $\mathrm{CB}$ filled SBR/NR blends in the past [22]. The reconstruction of the result from [22] is presented in Figure $5 b$ to compare with that of the present work. This contradiction can be explained by taking into consideration the presence of silica in the hybrid fillers. In the first mixing stage up to 14 min (Figure 4), a large part of NR molecules was attracted by the silica surface that leads to the fact that fewer NR molecules are available for wetting $\mathrm{CB}$. At the end of the mixing

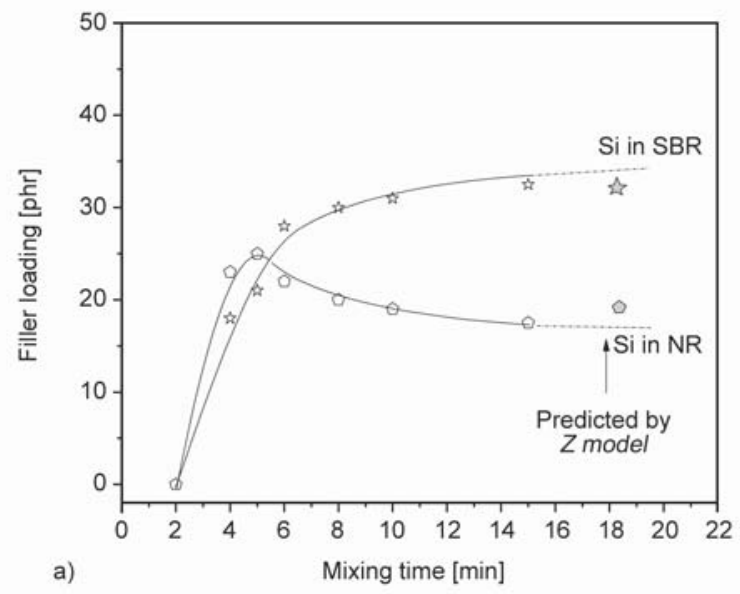

process, the filler localization of silica and $\mathrm{CB}$ in $\mathrm{B} 7$ determined by the wetting concept is corresponding very well to that predicted by the $Z$ model. A comparison between the kinetics of filler localization experimentally determined by the wetting concept, and the filler localization at an equilibrium theoretically predicted by our $Z$ model, provides a deeper insight into the filler transfer process taking place during the mixing proces.

It has been well known that the morphological investigation of the phase selective filler localization in highly filled rubber blends using electron microscopy fails because of a large amount of filler. As an example, an AFM image of B7 filled with $50 \mathrm{phr}$ silica and CB is shown in Figure 6a. It is obvious that the phase selective filler localization could not be evaluated in the blend. A reduction of the filler content in a blend may enable the visualization of the highly filled blend. A low filled SBR/NR blend containing $3 / 3 \mathrm{Si} / \mathrm{CB}$ was prepared for morphological investigation by means of AFM and TEM. It is seen from the AFM image (Figure 6b) that SBR and NR form a co-continuous phase morphology with silica and $\mathrm{CB}$ domains (white spots) mainly locating in the NR phase (dark phase). Nearly no filler is found in the SBR phase (light phase). Furthermore, from the TEM image (Figure 6c), large CB aggregates and small silica aggregates are clearly identified in the NR phase (light phase). According to the datasheet of the used fillers, silica has an average particle size of about $10 \mathrm{~nm}$, and the particle size of CB is $20 \mathrm{~nm}$. The observation of the morphology of the low filled blend was found not to be in line with the experimental determination and the prediction made for a highly filled blend, as presented in Figure 4. The change

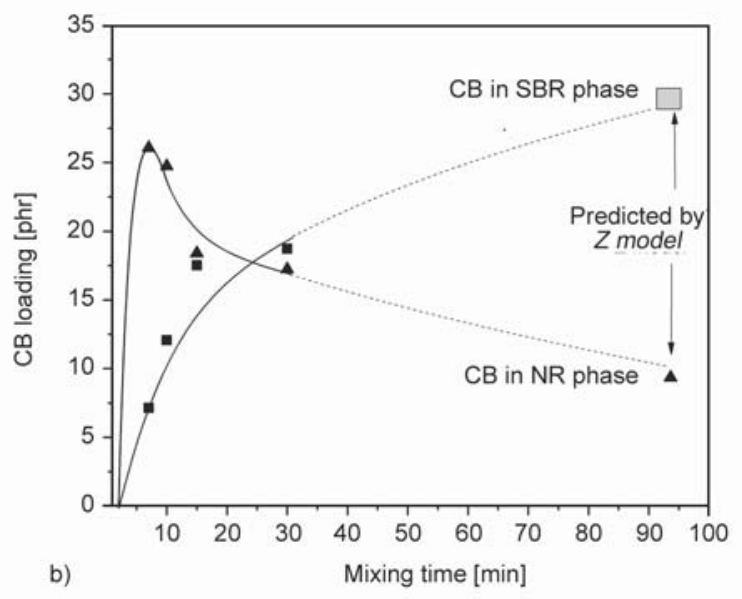

Figure 5. Kinetics of silica localization in SBR/NR blend (a) and CB in SBR/BR/NR blend (b) which were reconstructed using data from $[20,22]$. 

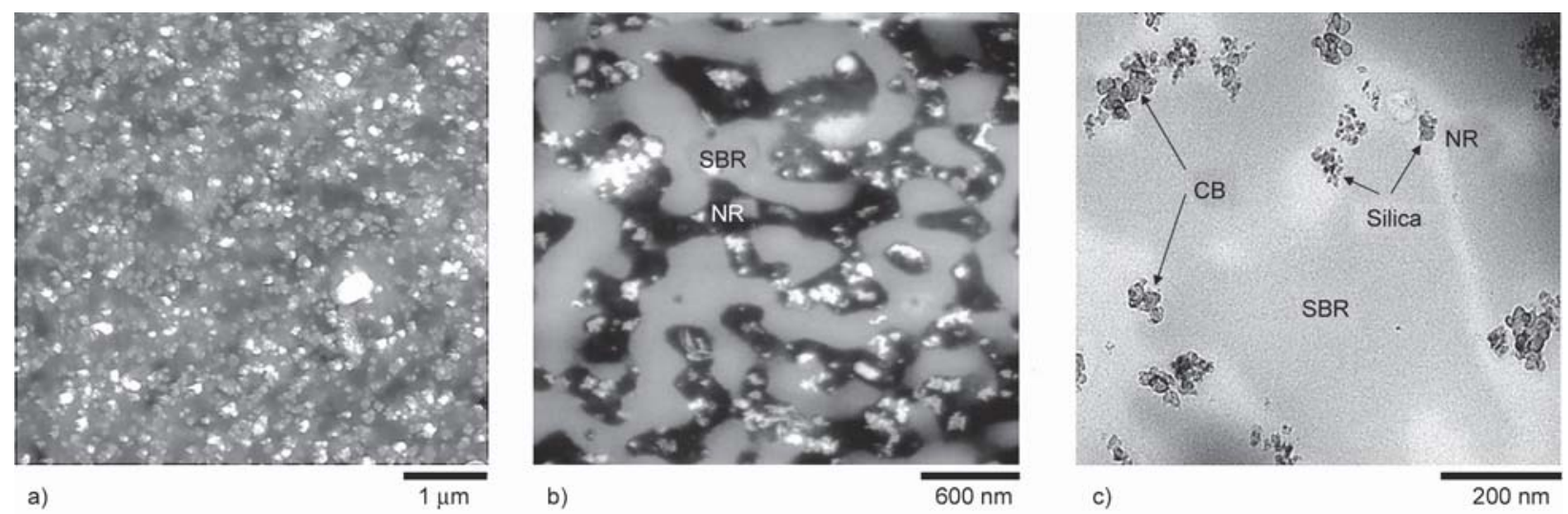

Figure 6. AFM (a) image of $25 / 25 \mathrm{Si} / \mathrm{CB}$ filled SBR/NR blend, AFM (b) and TEM (c) image of 3/3 Si/CB filled SBR/NR blend.

of filler localization behavior in rubber blends by variation of filler loading has also been reported in the literature [7, 29, 30]. Maiti et al. [7] found when the silica content was increased from 10 to $40 \mathrm{phr}$ in NR/epoxidized natural rubber (ENR) blends, the weight fraction of silica in the ENR phase decreased. Phewphong et al. [29] observed a significant influence of the silica loading on the filler localization in chlorinated polyethylene (CPE)/NR blends. He stated that the counter-balancing effects of relatively low viscosity of the NR phase and strong silica-CPE interaction, which is changed with increasing silica loading, may be responsible for the change of the silica localization. However, no satisfying explanation has been given so far. In order to make clear the contradiction of the results from a highly and low filled blend, the role of the curing additives used should be taken into consideration. For the preparation of a rubber product beside rubber and filler, different ingredients, including processing and curing additives, belong to indispensable ingredients. The adsorption of stearic acid, zinc oxide ( $\mathrm{ZnO})$ and $\mathrm{N}$-cyclohexylbenzothiazole-2-sulfenamide (CBS) on the surface of silica and other fillers like $\mathrm{CaCO}_{3}$ and $\mathrm{Mg}(\mathrm{OH})_{2}$ makes them more hydrophobic that enhances the rubber-filler interaction [31-37]. It was reported, for example, in [35], that the adsorbed $\mathrm{ZnO}$ on silica surface causes a reduction of silica surface energy from 66 to $35.5 \mathrm{mN} / \mathrm{m}$. Peña et al. [38] found that sulfur and CBS can be adsorbed on the CB surface that may be the reason for fast vulcanization kinetics. Stearic acid with the acidic character can interact with oxygen-containing groups on the $\mathrm{CB}$ surface by hydrogen bonding or acid-base interaction, because the $\mathrm{pH}$ value of $\mathrm{CB}$ ranges from 7.5 to $10 \mathrm{de}-$ pending on the $\mathrm{CB}$ type $[38,39]$. In our previous works [12] we reported the use of the method of the wetting concept as a tool for determination of the surface tension of silica, which changes during the mixing process due to the adsorption of stearic acid, $\mathrm{ZnO}$, and sulfur as well as CBS.

On the basis of the result reported in $[12,21]$, the surface tension of silica, which changes during the mixing process, can be estimated by the known additives/silica ratio. Using the master curve of filler localization shown in Figure 7, the filler localization depending on the change of filler surface tension can be easily explained. At high filler surface tension far away from $\gamma_{\mathrm{SBR}}$ an even localization of filler is nearly received because filler shows similar bad affinity to both blend phases. With decreasing $\gamma_{\mathrm{F}}$, the filler fraction in the SBR phase increases and nearly reaches the value of 1.0 when $\gamma_{\mathrm{F}} \rightarrow \gamma_{\mathrm{SBR}}$. Passing $\gamma_{\mathrm{SBR}}$, the filler fraction decreases because the affinity of the filler to SBR becomes worse, and to NR better. In this range, a very strong dependence of the filler

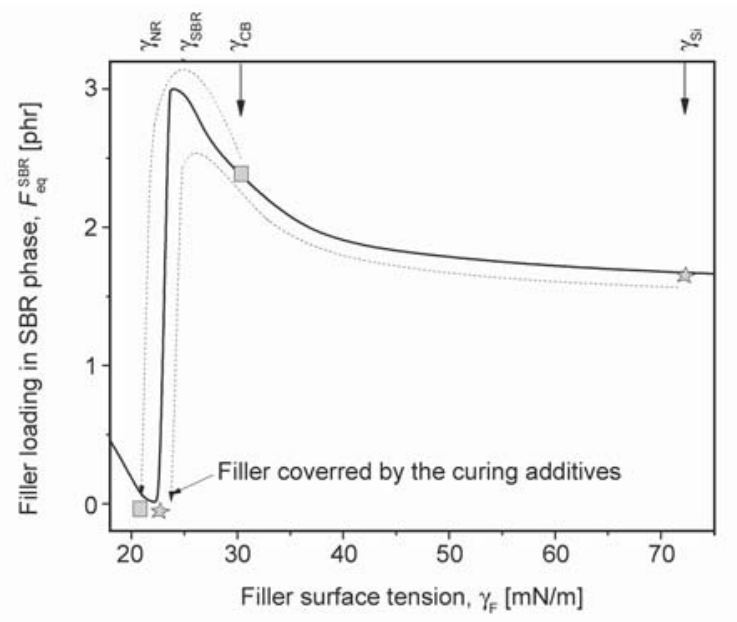

Figure 7. Master curve of silica and CB localization in $3 / 3$ $\mathrm{Si} / \mathrm{CB}$ filled SBR/NR blend according to the $Z$ model. 
localization on the filler surface tension is obtained. A small change of filler surface tension can lead to an extremely large change in filler localization. When $\gamma_{\mathrm{F}} \rightarrow \gamma_{\mathrm{NR}}$, an entire localization of filler in the NR phase is nearly obtained.

Keeping constant the loading of additives used (stearic acid, $\mathrm{ZnO}$, and $\mathrm{CBS}$ ) at $6.5 \mathrm{phr}$ in $3 / 3 \mathrm{Si} / \mathrm{CB}$ filled SBR/NR blend, a curing additives/silica ratio of $6.5 / 3$ is reached, which causes a reduction of silica surface tension from 70 to $22 \mathrm{mN} / \mathrm{m}$ according to our previous work $[12,21]$. Fitting silica surface tension $\gamma_{\mathrm{F}}=22 \mathrm{mN} / \mathrm{m}$ into the master curve of the $3 / 3$ $\mathrm{Si} / \mathrm{CB}$ filled SBR/NR blend, a complete localization of silica in the NR phase is predicted for the thermodynamic equilibrium state. A prediction of $\mathrm{CB}$ in this blend is not possible because of the lack of the surface tension of $\mathrm{CB}$ changed during the mixing process. Based on the fact that $\mathrm{CB}$ is completely localized in the NR phase (Figure $6 \mathrm{~b}$ and $6 \mathrm{c}$ ), we would suggest that the surface tension of $\mathrm{CB}$ reduces from 30.5 to about $22 \mathrm{mN} / \mathrm{m}$ due to the adsorption of curing additives on the surface. This result shows the huge influence of the additives on the rubber-filler interaction in rubber blends and its related morphology, particularly at low filler loading. The morphology of a low filled rubber blend can hardly be used for characterization of the highly filled rubber blend. That is the main reason for the development of an indirect method for the quantification of filler localization in highly filled rubber blends as done in the present work.

\subsection{Migration of hybrid fillers $\mathrm{Si} / \mathrm{CB}$ in SBR/NR blends}

Multi-step mixing has been often used for the generation of rubber blends with desired filler localization targeting to receive desired performances. In the present work, blends B1 to B6 were prepared by masterbatch mixing of corresponding masterbatches according to Table 2 .

Assuming that no filler migration took place during the masterbatch mixing, a blend series $\mathrm{C} 1$ to $\mathrm{C} 6$ can be theoretically generated. The phase selective localization of $\mathrm{Si} / \mathrm{CB}$ in $\mathrm{C} 1$ to $\mathrm{C} 6$ can be calculated using the filler loading added in each masterbatch and illustrated as seen in Figure 8. Applying the wetting concept to blend series $\mathrm{B}$, the filler localization of $\mathrm{Si} / \mathrm{CB}$ was experimentally determined and presented in Figure 8.

In spite of the mixing of masterbatches with different $\mathrm{Si} / \mathrm{CB}$ ratio, all the blends $\mathrm{B} 1$ to $\mathrm{B} 6$ show the similar

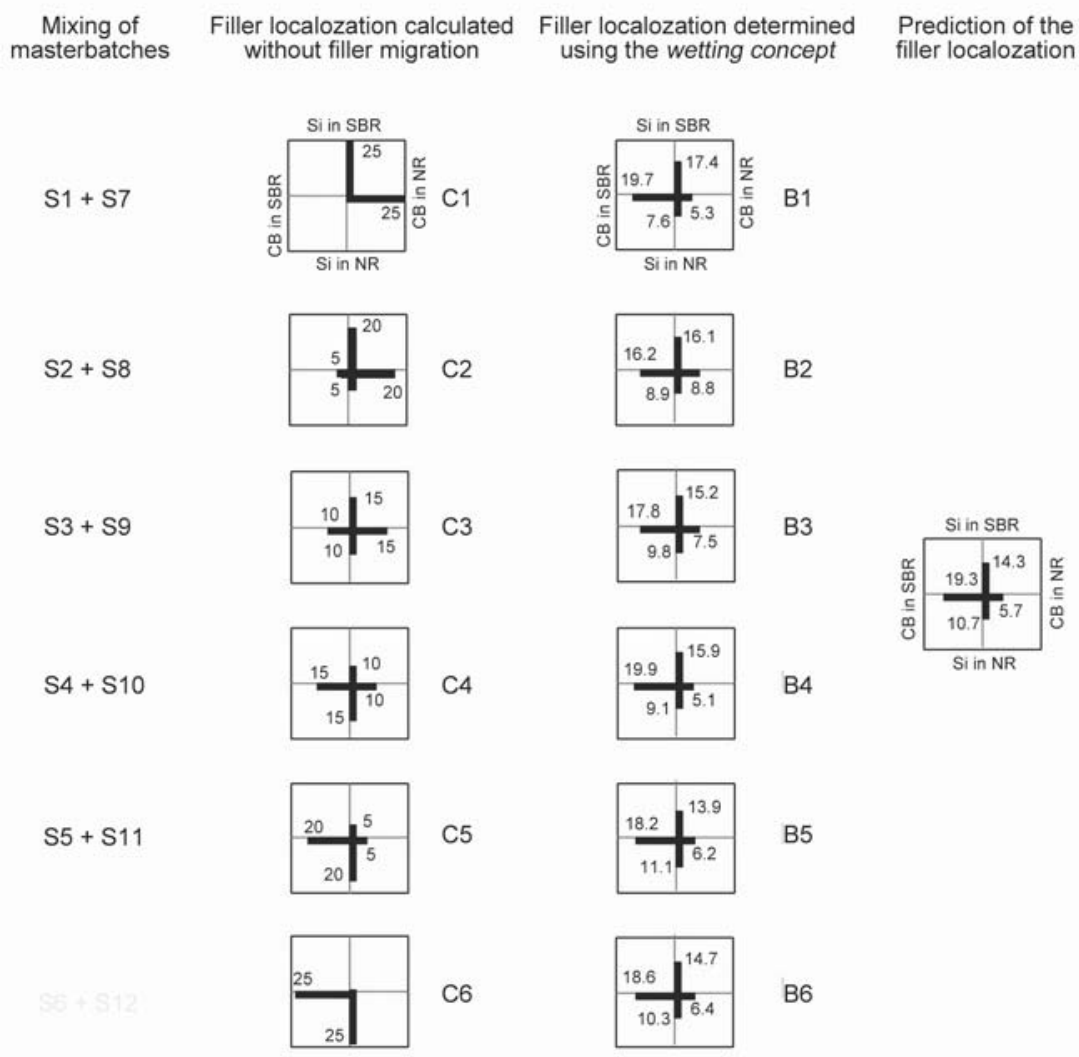

Figure 8. Filler localization in blends $\mathrm{C} 1$ to $\mathrm{C} 6$ calculated without filler migration and B1 to B6 determined experimentally by means of the wetting concept, as well as predicted by means of the $Z$ model. 
filler localization with a small deviation. They are corresponding to the result of blend $\mathrm{B} 7$ experimentally determined from single-step mixing and to that predicted by the $Z$ model. They differ significantly from that of the calculated blend series $\mathrm{C}$. The difference in filler localization between blend $\mathrm{C}$ and $\mathrm{B}$ is attributed to the filler migration during masterbatch mixing. A very strong filler migration is observed in B1 with 19.7 phr CB migrating from the NR phase to the SBR phase and in $\mathrm{B} 6$ with $14.7 \mathrm{phr}$ silica migrating from the NR phase to the SBR phase. It is worth noting that in blend series $\mathrm{C}$ the $\mathrm{Si} / \mathrm{CB}$ loading of $25 \mathrm{phr}$ was kept constant in each rubber phase. However, the experimental result from the wetting concept pointed out that in blends $\mathrm{B} 1$ to $\mathrm{B} 6$, about $34 \mathrm{phr} \mathrm{Si} / \mathrm{CB}$ are located in the SBR phase, and $16 \mathrm{phr} \mathrm{Si} / \mathrm{CB}$ are found in the NR phase.

\subsection{Mechanical testing}

The results of the tensile test are represented in Figures $9 \mathrm{a}$ and $9 \mathrm{~b}$, respectively, for the SBR and NR compounds with various $\mathrm{Si} / \mathrm{CB}$ ratios. For both series, the tensile strength increases, and elongation at break decreases if the silica fraction decreases correspondingly. This behavior indicates the increase of crosslink density in compounds, which happens as the adsorption of the curing additives on the silica surface is decreased as discussed in [31-37, 40, 41]. In addition, the improvement of tensile strength at lower silica content may relate to the decrease of the silica-silica interaction due to the bad silica dispersion. Taking into consideration the co-continuous morphology of the SBR/NR blend shown in Figure 6, the properties of the blend series $\mathrm{C}$, for example, $\mathrm{C} 1$, $\mathrm{PC} 1$ can be estimated as an average value of those of the blend components $P_{\mathrm{S} 1}$ and $P_{\mathrm{S} 7}$ using Equation (22):

$P_{\mathrm{C} 1}=\frac{P_{\mathrm{S} 1}+P_{\mathrm{S} 7}}{2}$

The tensile strength and elongation at break of blends $\mathrm{C} 1$ to $\mathrm{C} 6$ were calculated using Equation (22) and presented in Figure 9c. The tensile strength shows a maximal and minimal value at $\mathrm{C} 2$ and $\mathrm{C} 5$, respectively; meanwhile, the elongation at break continuously increases from $\mathrm{C} 1$ to $\mathrm{C} 6$. The dependence of the mechanical properties of the series blend $\mathrm{C}$ is similar to that of polymer blends containing hybrid fillers which have been frequently reported in the literature $[5,42-44]$.
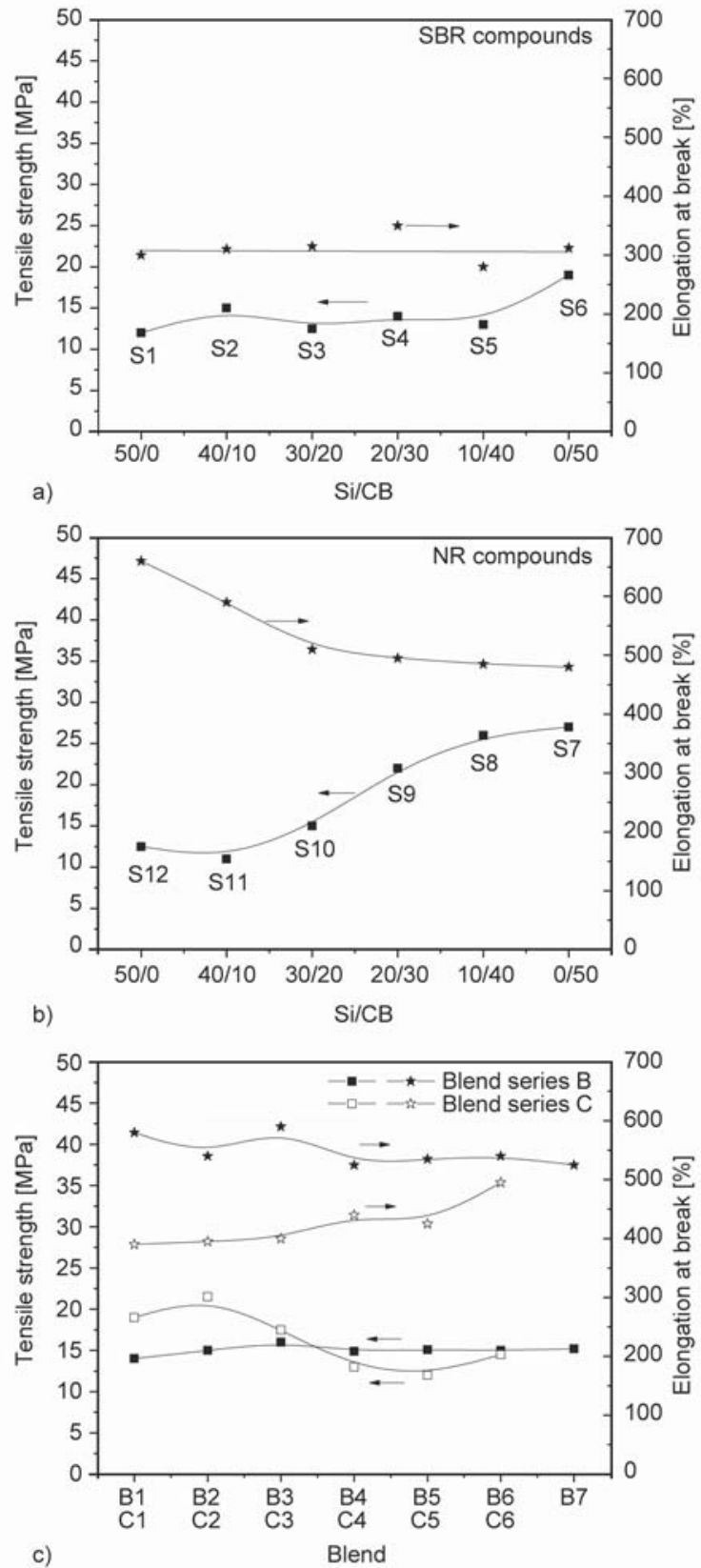

Figure 9. Tensile strength and elongation at break from the tensile test of series S1-S6 (a), S7-S12 (b), B and $\mathrm{C}$ (c).

The tensile properties of the blends B1 to B6 were experimentally characterized and presented in Figure 9c. It is obvious that the tensile strength and elongation at break of six blends are similar, respectively. Particularly, the measured elongation at break is much better than those calculated.

The tearing resistance of both series $\mathrm{S}$ is presented in Figure 10a. It is in the range of $4 \mathrm{~N} / \mathrm{mm}$ for all the SBR compounds. NR compounds containing high silica fraction show the same low tearing resistance as the SBR compounds. With increasing CB fraction, the tearing resistance of the NR compounds increases 


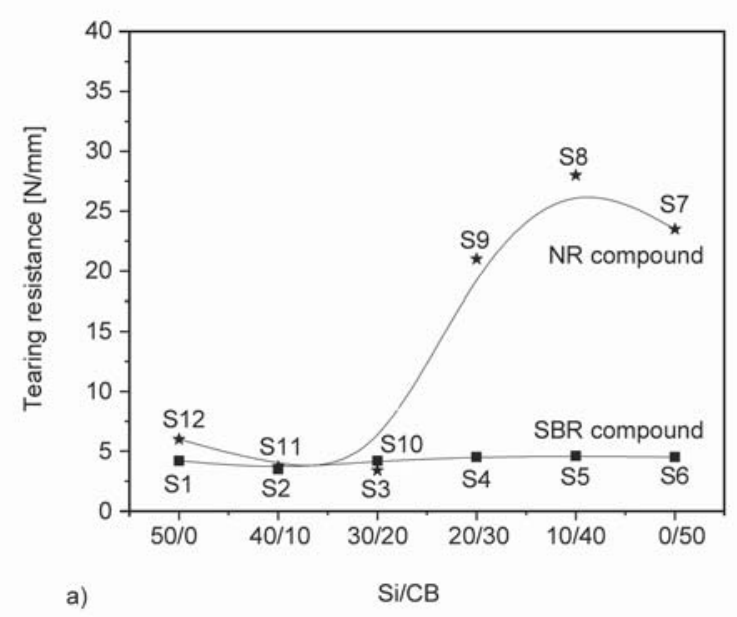

Figure 10. Tearing resistance of S series (a), B and C series (b).

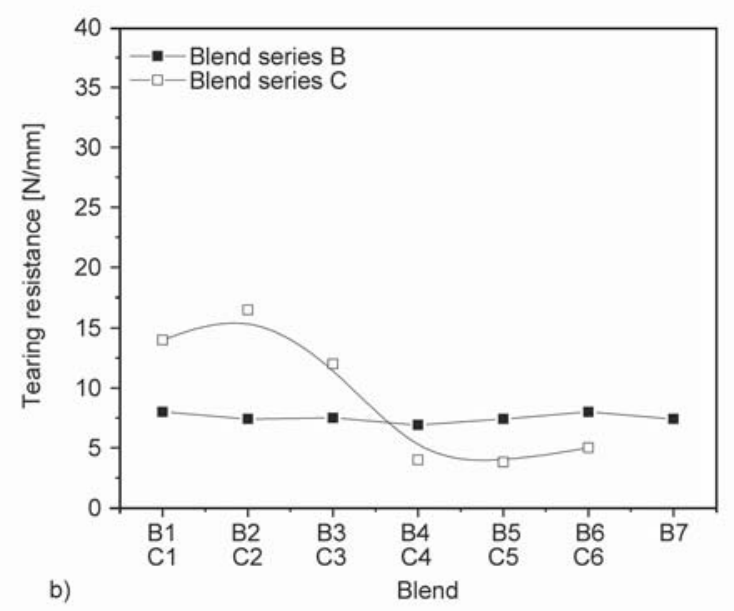

b)

means of different mixing techniques can be justified by the thermodynamic aspect, which can be representatively predicted by the $Z$ model using the surface tension values of the blend components. The adsorption of the curing additives on the filler surface alters the surface energy of silica and $\mathrm{CB}$, which in turn influences the localization of fillers in the hybrid filled rubber blends, especially at low filler loading. Thus, the morphological investigation made by electron microscopy for low filled rubber blends can be hardly applied for the description of the filler localization of hybrid fillers in rubber blends at high filler loading. That is the main reason for the development of an indirect method as done in the present work.

\section{Acknowledgements}

The authors thank the Deutsche Forschungsgemeinschaft (Project Nr. DFG WI 2671/2-1) for the financial support. We thank Dr. Malanin (IPF Dresden) for carrying out the measurements of FTIR.

\section{References}

[1] Byers J. T.: Fillers for balancing passenger tire tread properties. Rubber Chemistry Technology, 75, 527-548 (2000). https://doi.org/10.5254/1.3547681

[2] Al-Hartomy O. A., Al-Ghamdi A. A., Al-Said S. F., Dishovsky N., Ward M. B., Malinovka P., Mihaylov M.: A comparative study of the phase distribution in carbon-silica hybrid fillers for rubber obtained by different methods. Materials Sciences and Applications, 5, 685697 (2014).

https://doi.org/10.4236/msa.2014.510070

[3] Abdul Salim Z. A. S., Hassan A., Ismail H.: A review on hybrid fillers in rubber composites. Polymer-Plastics Technology and Engineering, 57, 523-539 (2018). https://doi.org/10.1080/03602559.2017.1329432 
[4] Zhang Y., Ge S., Tang B., Koga T., Rafailovich M. H., Sokolov J. C., Peiffer D. G., Li Z., Dias A. J., McElrath K. O., Lin M. Y., Satija S. K., Urquhart S. G., Ade H., Nguyen D.: Effect of carbon black and silica fillers in elastomer blends. Macromolecules, 34, 7056-7065 (2001).

https://doi.org/10.1021/ma010183p

[5] Decol M., Pachekoski W. M., Segundo E. H., Pinheiro L. A., Becker D.: Effects of processing conditions on hybrid filler selective localization, rheological, and thermal properties of poly(e-caprolactone)/poly(lactic acid) blends. Journal of Applied Polymer Science, 137, 48711/1-48711/10 (2019).

https://doi.org/10.1002/app.48711

[6] Sumita M., Sakata K., Hayakawa Y., Asai S., Miyasaka K., Tanemura M.: Double percolation effect on the electrical conductivity of conductive particles filled polymer blends. Colloid Polymer Science, 270, 134-139 (1992).

https://doi.org/10.1007/BF00652179

[7] Maiti S., De S. K., Bhowmick A. K.: Quantitative estimation of filler distribution in immiscible rubber blends by mechanical damping studies. Rubber Chemistry and Technology, 65, 293-302 (1992).

https://doi.org/10.5254/1.3538612

[8] Klüppel M., Schuster R. H., Schaper J.: Carbon black distribution in rubber blends: A dynamic-mechanical analysis. Rubber Chemistry and Technology, 72, 91108 (1999).

https://doi.org/10.5254/1.3538797

[9] Schuster R. H., Meier J., Klüppel M.: The role of interphase in filler partition in rubber blends. Kautschuk Gummi Kunststoffe, 53, 663-674 (2000).

[10] Meier J. G., Klüppel M., Geisler H., Schuster R. H.: Control of physical properties of elastomers: Characterization of blend morphology of carbon black and silica system. Part I. Kautschuk Gummi Kunststoffe, 58, 82-89 (2005).

[11] Hess W. M., Chirico V. E.: Elastomer blend properties - Influence of carbon black type and location. Rubber Chemistry and Technology, 50, 301-326 (1977). https://doi.org/10.5254/1.3535145

[12] Le H. H., Oßwald K., Ilisch S., Hoang X. T., Heinrich G., Radusch H-J.: Master curve of filler localization in rubber blends at an equilibrium state. Journal of Materials Science, 47, 4270-4281 (2012).

https://doi.org/10.1007/s10853-012-6277-6

[13] Massie J. M., Hirst R. C., Halasa A. F.: Carbon black distribution in NR/polybutadiene blends. Rubber Chemistry and Technology, 66, 276-285 (1993).

https://doi.org/10.5254/1.3538311

[14] Sircar A. K., Lamond T. G., Pinter P. E.: Effect of heterogeneous carbon black distribution on the properties of polymer blends. Rubber Chemistry and Technology, 47, 48-56 (1974).

https://doi.org/10.5254/1.3540430
[15] Herrmann V., Unseld K., Fuchs H. B.: Atomic force microscopy for the investigation of inhomogenous polymer system. Kautschuk Gummi Kunststoffe, 54, 453457 (2001).

[16] Appel R., Zerda T. W., Waddell W. H.: Raman microimaging of polymer blends. Applied Spectroscopy, 54, 1559-1566 (2000).

https://doi.org/10.1366/0003702001948808

[17] Cotten G. R., Murphy L. J. B.: Mixing of carbon black with rubber: V. Analysis of SBR/BR-blends. Kautschuk Gummi Kunststoffe, 41, 54-58 (1988). https://doi.org/10.5254/1.3536207

[18] Le H. H., Ilisch S., Kasaliwal G. R., Radusch H-J.: Method for the characterization of phase specific filler distribution in rubber blends using thermogravimetric analysis on the rubber-filler gel. Kautschuk Gummi Kunststoffe, 60, 241-248 (2007).

[19] Le H. H., Reincke K., Das A., Stöckelhuber K-W., Wießner S., Pham T., Do Q. K., Hoang X. T., Grellmann W., Heinrich G., Radusch H-J.: Filler wetting in miscible ESBR/SSBR blends and its effect on mechanical properties. Macromolecular Materials and Engineering, 301, 414-422 (2016). https://doi.org/10.1002/mame.201500325

[20] Le H. H., Keller M., Hristov M., Ilisch S., Xuan T. H., Do Q. K., Pham T., Stöeckelhuber K-W., Heinrich G., Radusch H-J.: Selective wetting and localization of silica in binary and ternary blends based on styrene butadiene rubber, butadiene rubber, and natural rubber. Macromolecular Materials and Engineering, 298, 10851099 (2013).

https://doi.org/10.1002/mame.201200307

[21] Le H. H., Hamann E., Ilisch S., Heinrich G., Radusch H-J.: Selective wetting and dispersion of filler in rubber composites under influence of processing and curing additives. Polymer, 55, 1560-1569 (2014).

https://doi.org/10.1016/j.polymer.2014.02.002

[22] Sarma A. D., Le H. H., Das A., Wießner S., Stöckelhuber K. W., Bhowmick A. K., Heinrich G.: Determination of phase specific localization of carbon black in ternary rubber blends: A macroscopic approach by Fourier transform infrared spectroscopy (FTIR). Polymer, 150, 6471 (2018).

https://doi.org/10.1016/j.polymer.2018.07.013

[23] Le H. H., Sriharish M. N., Henning S., Klehm J., Menzel M., Frank W., Wießner S., Das A., Stöckelhuber K. W., Heinrich G., Radusch H-J.: Dispersion and distribution of carbon nanotubes in ternary rubber blends. Composite Science and Technology, 90, 180-186 (2014). https://doi.org/10.1016/j.compscitech.2013.11.008

[24] Le H. H., Das A., Basak S., Tahir M., Wießner S., Fischer D., Reuter U., Stöckelhuber K. W., Bhowmick A. K., Do Q. K., Heinrich G., Radusch H-J.: Effect of different ionic liquids on the dispersion and phase selective wetting of carbon nanotubes in rubber blends. Polymer, 105, 284-297 (2016). https://doi.org/10.1016/j.polymer.2016.10.045 
[25] Ali Z., Le H. H., Ilisch H., Radusch H-J.: Morphology development in nanoclay filled rubber compounds and rubber blends detected by online measured electrical conductance. Journal of Materials Science, 44, 6427 6436 (2009). https://doi.org/10.1007/s10853-009-3892-y

[26] Jönsson U., Malmqvist M., Rönberg I.: Immobilization of immunoglobulins on silica surfaces. Stability. Biochemical Journal, 227, 363-371 (1985).

https://doi.org/10.1042/bj2270363

[27] Stöckelhuber K. W., Das A., Jurk R., Heinrich G.: Contribution of physico-chemical properties of interfaces on dispersibility, adhesion and flocculation of filler particles in rubber. Polymer, 51, 1954-1963 (2010). https://doi.org/10.1016/j.polymer.2010.03.013

[28] Le H. H., Oßwald K., Ilisch S., Pham T., Stöckelhuber K. W., Heinrich G., Radusch H-J.: Silica transfer in ternary rubber blends: Calculation and experimental determination. Macromolecular Materials and Engineering, 297, 464-473 (2012).

https://doi.org/10.1002/mame.201100217

[29] Phewphong P., Saeoui P., Sirisinha C.: Mechanism of silica reinforcement in CPE/NR blends by the use of rheological approaches. Journal of Applied Polymer Science, 107, 2638-2645 (2008).

https://doi.org/10.1002/app.27444

[30] Wootthikanokkhan J., Rattanathamwat N.: Distribution of carbon black in natural rubber/acrylic rubber blends. Journal of Applied Polymer Science, 102, 248-256 (2006).

https://doi.org/10.1002/app.23642

[31] Ahn S. H., Kim S. H., Lee S. G.: Surface-modified silica nanoparticle-reinforced poly(ethylene 2,6-naphthalate). Journal of Applied Polymer Science, 94, 812-818 (2004).

https://doi.org/10.1002/app.21007

[32] Deshmukh G. S., Pathak S. U., Peshwe D. R., Ekhe J. D.: Effect of uncoated calcium carbonate and stearic acid coated calcium carbonate on mechanical, thermal and structural properties of poly(butylene terephthalate) (PBT)/calcium carbonate composites. Bulletin Materials Science, 33, 277-284 (2010).

https://doi.org/10.1007/s12034-010-0043-7

[33] Osman M. A., Atallah A., Suter U. W.: Influence of excessive filler coating on the tensile properties of LDPEcalcium carbonate composites. Polymer, 45, 1177-1183 (2004).

https://doi.org/10.1016/j.polymer.2003.12.020

[34] Huang H., Tian M., Yang J., Li H., Liang W., Zhang L., Li X.: Stearic acid surface modifying $\mathrm{Mg}(\mathrm{OH})_{2}$ : Mechanism and its effect on properties of ethylene vinyl acetate $\mathrm{Mg}(\mathrm{OH})_{2}$ composites. Journal of Applied Polymer Science, 107, 3325-3331 (2008).

https://doi.org/10.1002/app.24894

[35] Kosmalska A., Zaborski M., Ślusarski L.: Adsorption of curatives and activity of silica toward elastomers. Macromolecular Symposia, 194, 269-275 (2003). https://doi.org/10.1002/masy.200390092
[36] Laning S. H., Wagner M. P., Sellers J. W.: The determination of zinc oxide in rubber vulcanizates by X-ray diffraction. Journal of Applied Polymer Science, 2, 225-230 (1959).

https://doi.org/10.5254/1.3542206

[37] Liauw C. M., Lees G. C., Hurst S. J., Rothon R. N., Ali S.: Effect of silane-based filler surface treatment formulation on the interfacial properties of impact modified polypropylene/magnesium hydroxide composites. Composites Part A: Applied Science and Manufacturing, 29A, 1313-1318 (1998). https://doi.org/10.1016/S1359-835X(97)00132-2

[38] Peña J. M., Allen N. S., Edge M., Liauw C. M., Valange B.: Interactions between carbon black and stabilisers in LDPE thermal oxidation. Polymer Degradation and Stability, 72, 163-174 (2001). https://doi.org/10.1016/S0141-3910(01)00016-7

[39] Lawandy S. N., Halim S. F., Darwish N. A.: Structure aggregation of carbon black in ethylene-propylenediene polymer. Express Polymer Letters, 3, 152-158 (2009). https://doi.org/10.3144/expresspolymlett.2009.20

[40] Zafarmehrabian R., Gangali S. T., Ghoreishy M. H. R., Davallu M.: The effects of silica/carbon black ratio on the dynamic properties of the tread compounds in truck tires. E-Journal of Chemistry, 9, 1102-1112 (2012). https://doi.org/10.1155/2012/571957

[41] Noriman N. Z., Ismail H.: Properties of styrene butadiene rubber (SBR)/recycled acrylonitrile butadiene rubber (NBRr) blends: The effects of carbon black/silica (CB/Sil) hybrid filler and silane coupling agent, Si69. Journal of Apllied Polymer Science, 124, 19-27 (2012). https://doi.org/10.1002/app.34961

[42] Guo L., Xiao C., Wang H., Chen L., Zhang X., Zheng K., Tian X.: Thermally conductive polystyrene/epoxy nanocomposites fabricated by selective localization of hybrid fillers. Colloid Polymer Science, 294, 901-910 (2016). https://doi.org/10.1007/s00396-016-3845-3

[43] Xiao C., Leng X., Wang H., Su Z., Zhang X., Chen L., Zheng K., Tian X.: Synergistic effect of selectively distributed AlN/MWCNT hybrid fillers on the morphological, mechanical and thermal properties of polycarbonate/maleated poly[styrene- $b$-(ethylene- $c o$-butylene)- $b$ styrene] triblock copolymer (SEBS-g-MA) composites. Materials Research Express, 4, 025101/1-025101/12 (2017).

https://doi.org/10.1088/2053-1591/aa5b60

[44] Wei Y., Huang R., Dong P., Qi X. D., Fu Q.: Preparation of polylactide/poly(ether)urethane blends with excellent electro-actuated shape memory via incorporating carbon black and carbon nanotubes hybrids fillers. Chinese Journal of Polymer Science, 36, 1175-1186 (2018).

https://doi.org/10.1007/s10118-018-2138-3 